\title{
Facilitating workforce development: The economic developer's role in supporting economic stability in medium and small resource-based British Columbian cities
}

\begin{abstract}
Christina Doll
The availability of a talented workforce is increasingly being cited as a barrier to growth by businesses across Canada. This worker shortage is particularly challenging for organizations looking to expand in medium and small resource-based cities. This is due to an increase in outmigration to large cities by people seeking knowledge economy based employment and negative perceptions of resource-based cities. These factors hinder employer's ability to attract people to their smaller resource-reliant communities from other cities. Economic developers in these smaller cities can adjust to these changing realities by highlighting their community's strengths in relation to larger cities to attract and retain the skilled talent needed to support the growth of their existing businesses and to attract new business. Economic developers in the Kootenays, Prince George and Quesnel have all recognized this opportunity and the work being done in these communities to increase the population base can be used as a model by other communities grappling with similar workforce attraction and retention issues.
\end{abstract}

Keywords: economic development, workforce, population, attraction and retention, natural resources, urbanization, outmigration

\section{Introduction}

Adapting to quickly shifting economic realities is one of the biggest challenges facing economic developers. This is particularly true in traditionally natural resource-dependent medium and small cities in British Columbia (BC) where diversification and a strong workforce are necessary to maintain economic vitality. Access to skilled labour is one of the bigger challenges faced by these communities. According to O'Farrell it is “the most important factor in a company's location decision. A talented labour pool is thus no longer a luxury; it is a staple for competition in the global marketplace" (O'Farrell, 2015). Large cities have typically excelled at business attraction because they offer a wide range of amenities, a large and diverse workforce, and have established reputations leading to name recognition. Along with expanding urbanization, these attributes allow for successful population attraction leading to continued growth. The competition between large and medium and small resource-based cities for a robust workforce has been further tightened by the shift toward a knowledge-based economy. This shift is 
happening more quickly in larger cities, ultimately making them more attractive to work and live in than smaller communities.

Economic developers in medium and small BC communities can adjust to these changing realities by leveraging their community's strengths, particularly those that are not available in larger centres, to attract and retain skilled talent needed to assist the growth of existing businesses and to assist economic diversification through new business attraction. An examination of the current state of BC's workforce will highlight the challenges faced by economic developers in medium and small resource-based cities along with the increasing importance of including workforce attraction tactics in economic development strategies. The efforts of economic developers in several medium and small resource-based cities in the Kootenay and the Cariboo regions of $\mathrm{BC}$ to attract population will provide evidence of the effectiveness of this approach in ensuring a community's economic strength. Workforce attraction strategies employed by economic developers in these communities can be further enhanced through retention strategies that counter outmigration. This can be accomplished by providing training for existing residents that develops or enhances their skills to align with the new demands of a knowledge-based economy.

\section{The implications of a growing knowledge-based economy for natural resource-based cities in $\mathrm{BC}$}

There is no doubt that developed countries such as Canada are increasingly moving toward a knowledge-based economy (Cocolakis-Wormstall, 2018). A knowledge-based economy is one that is increasingly built on knowledge and information and shifts away from an economy based on the production of goods and services: "Knowledge is now recognized as the driver of productivity and economic growth, leading to a new focus on the role of information, technology, and learning in economic performance" (Government of Canada, 2017a). For resource-based or single industry cities, like many communities located outside of the Lower Mainland region of BC, the shift toward a knowledge-based economy is happening more slowly. These communities must compete for talent and investment with larger cities with established knowledge-based economies for the talent needed to sustain traditional manufacturing and natural resource extraction activities and to attract new investment (Garmise, Ghosh, et al., 2015). This lag in shifting to a knowledge-based economy is further complicated by the changing state of BC's workforce.

\section{The current state of the workforce in medium and small BC communities}

$\mathrm{BC}$, like the rest of Canada, is aging - baby boomers are retiring and there are not enough people in successive generations to fill the resulting vacancies; with most job vacancies and new jobs being in major centres, competition for skilled talent is increasing (Halseth, Markey, Ryser, 
2015). Further complicating this situation for medium and small resource-based cities is that "[o]ne of the significant stories in non-metropolitan BC's demographic landscape is that of accelerated population aging. While the Canadian population is aging, non-metropolitan BC often shows a trend of aging at a faster rate" (Halseth, Markey, Ryser, 2015). According to the British Columbia Labour Outlook, "[i]t is forecast that there will be 917,000 job openings between now and 2027. Most of these new job openings (70 percent) will be due to workers leaving the workforce, mostly through retirement. While some older workers may choose to work a little past retirement age, there will not be enough of them to solve the expected shortage of workers" (GBC, 2017). The report also reveals that two-thirds of these job openings will be in the Mainland/Southwest, with a smaller proportion in other parts of the province where medium and small cities are located (GBC, 2017). The cities that typically attract people will continue to do so as more jobs become available, creating increased difficulty for the attraction and retention of people to medium and small cities where a lesser proportion of jobs will be available. Furthermore, while the presence of natural resources and a geographically advantageous location were once enough to give a community a competitive advantage, the presence of a strong workforce is crucial in today's economy (Garmise et al., 2015). This means those medium and small resource-based cities suffering from outmigration need to focus on workforce attraction to regain a competitive advantage.

\section{Attracting a skilled workforce by promoting community assets}

With numerous strategies available for attracting skilled talent, it can be difficult for an economic developer to decide which approach will deliver the best results for their community. According to Garmise et al. (2015) some options include: "improving skills of the workforce; helping businesses meet their human resource demands; providing channels for businesses and workers to connect; educating young people and laid-off workers; job training; and assisting workers to improve their basic skills, hard skills, and soft skills". Economic developers in medium and small resource-based cities in $\mathrm{BC}$ can take immediate action to meet workforce demands by marketing the strengths of their communities compared to larger cities. As noted in the Canadian Edition of Workforce Development, marketing and attraction were traditionally used by economic developers to attract, retain and expand business, but these strategies are also proving effective in addressing workforce challenges (Garmise et al., 2015). However, as opposed to providing information about a community's infrastructure, available land, tax rates, development incentives and the like, it is important to focus on elements that make that community an attractive place to live, as "[t]he most economically successful areas are also very nice places to live, offering residents safe, attractive neighbourhoods along with a number of leisure and entertainment options" (Garmise et al., 2015). Many medium and small BC communities are nice places to live and have ample employment opportunities; the challenge for these communities is the lack of corresponding reputation for being a nice place to live and work, or they are simply unknown, compared to larger BC communities such as Vancouver, 
Kelowna and Victoria. Reputation can have a significant impact on a community's economy, so economic developers working in communities suffering from negative brand image should develop marketing campaigns that improve the perception of their communities (Garmise et al., 2015). Regardless of the situation, economic developers must determine several key factors prior to marketing a community such as: what makes their community a desirable place to live, what demographics and markets to target, and the best marketing strategy to employ. In several medium and small natural resource-based BC communities, economic developers have already taken steps to market their communities. This paper will examine the various approaches taken, identify what has worked and what can be replicated in similar sized communities and, finally, consider how these communities can build on their existing strategies.

\section{Case Studies}

\section{Case study 1: The Kootenays, BC-Imagine Kootenay}

The Kootenays is a region of $\mathrm{BC}$ better-known for its majestic beauty and for attracting tourists rather than new residents as many of the communities in the Kootenays are quite small. It is also associated with "[n] atural resources [which,] provide a large proportion of the jobs through mining and related activities, as well as forestry and lumber processing" (Imagine Kootenay). "Imagine Kootenay" is a website and marketing campaign that was born out of partnerships forged across the region with the purpose of attracting not only investment and business but also workforce over the long-term. As noted in a news release announcing the program,

"[t]he mandate of...Imagine Kootenay endeavours to build on the momentum of...two [existing] programs, Work West Kootenay and Invest Kootenay, through a marketing strategy that is geared to promote investment and labour market opportunities throughout the entire Kootenay and Boundary region” (Connery, 2016, p. 1).

Invest Kootenay was spearheaded by Community Futures Central Kootenay, which joined forces with other economic development organizations, local governments, and Chambers of Commerce. Partner communities and regions include Nelson and area, Kootenay Lake, Castlegar, Trail, Rossland and area, Nakusp, Revelstoke, Boundary Country, Golden, Columbia Valley, Fernie, Kimberley and Sparwood (Connery, 2016). The largest population of these communities surpasses 10,000 and the smallest communities range in the hundreds to low thousands, with a combined population of approximately 146,300 (WorkBC, n.d.). These communities banded together knowing they would have a better chance of attracting workforce as a region and, as a result, retaining and attracting business (Government of Canada, 2017a).

The Imagine Kootenay marketing campaign is built on a website promoted via social media and billboard advertising. The website has been divided into Work, Invest and Live sections. Each 
section provides resources tailored to an intended audience. The Work section provides information about key employers in the region, industry information, resources for entrepreneurs and a blog and podcast that focuses on work and entrepreneurial opportunities in the region. This section is complemented by the Live section that profiles different regional partners, provides information about educational opportunities, links to resources needed to assist those who are considering calling the Kootenay area home, and links to the blog and podcast webpages.

To promote the website to those who visit the Kootenays and are considering calling the area home, a large billboard advertisement was erected on a main highway through the Kootenays focusing on a variation of the slogan "Imagine Kootenay: Your better life". This billboard targets those who "[pack] up to go home with a sense of longing and regret at having to leave" (Connery, 2016). The hope is that " $[\mathrm{t}]$ his new signage should twig some reflection, pull at the heartstrings, inspire more fully their dreams of relocating to the Kootenays and how much more possible than ever before it is to make those dreams a reality" (Connery, 2016). This same objective and the other objectives of Imagine Kootenay are also shared via Twitter, which had over 1,500 followers, and Facebook, which had over 2,000 likes as of March 2018.

Imagine Kootenay appears to have been successful in achieving its goals of attracting not only investment and business, but also workforce to support new and existing business. Small population increases have been recorded by the 2016 Census profiles for the communities involved in "Imagine Kootenay". For example, the population increased by $14.8 \%$ in Invermere, $11.6 \%$ in Kimberley, $5.7 \%$ in Revelstoke, $3.3 \%$ in Nelson, $2.9 \%$ in Castlegar, $0.4 \%$ in Trail, and 0.2\% in Golden between 2011 and 2016 (Government of Canada, 2017b). Furthermore, the Imagine Kootenay program has been recognized by the BC Economic Development council "as a best practice for regional and multi-community economic development models" (Milner, n.d.). Imagine Kootenay has also resulted in investment success: "2,000 potential investors have registered their interest in the Kootenay region and 35 verified investments in Invest Kootenay listed opportunities representing \$9.8 million in direct investment” (Milner, n.d.).

\section{Case study 2: Prince George, BC-Move Up Prince George}

The city of Prince George has a population of 74,003 and is located in the Cariboo Region of BC. Despite the city having a diverse economy, it has a strong reputation as a forestry town. In 2014, the City's former economic development entity, Initiatives Prince George (IPG), commissioned a Workforce Intelligence Study that confirmed this reputation coupled with a low unemployment rate left Prince George with a small talent pool for employers which proved detrimental to business growth (R.A. Malatest \& Associates, 2014). According to this study, “[o]ne of Prince George's greatest stumbling blocks for attraction is a perception gap...Prince George is more often than not seen by Canadians as high in crime; economically depressed; and not worth relocating to for employment." The study goes on to say, "[t]he labour force has not 
grown sufficiently in recent years to satisfy demands for workers, and in 2013 it suffered a contraction due to such factors as net out-migration, a falling participation rate, and retirement." (R.A. Malatest \& Associates, 2014). In response to these challenges the marketing campaign Move Up Prince George was born. This campaign was created by IPG and is currently managed by the City's Economic Development Division.

In addition to uncovering workforce attraction challenges, the Workforce Intelligence Study identified the best approach to take in marketing Prince George to assist employers in attracting skilled talent. The study examined the city's economic recovery, workforce shortages, migration patterns, perception gap, its marketability, and cities to target in any marketing efforts (R.A. Malatest \& Associates, 2014). IPG used this study and the recommendations it contained to develop a website and national marketing plan with the dual-goal of assisting local employers in attracting skilled talent and changing perceptions of Prince George in order to attract new residents and, as a result, business. The campaign was focused on the features of Prince George that highlighted its marketability, including low cost of housing and overall affordability, high number of available jobs, a teaching hospital and cancer care centre, short commute times, and a relaxed lifestyle that offers a mix of urban amenities and a large variety of outdoor activities located in or within a short drive of the city.

The Move Up Prince George website acts as a digital relocation guide for use by employers to recruit new employees or by people looking for a new place to live. The website represents the first comprehensive online source for information about moving to and working/living in Prince George. The website highlights the city's strengths through a top 10 list of reasons to make a move to Prince George. It also provides information about working in Prince George that includes a career search page, and offers a detailed amenities map to help people visualize living in Prince George and to assist them in choosing in which neighbourhood to live based on nearby amenities. Central to the website is a focus on local people and stories; all photographs and videos on the website feature people who have moved to and/or live in Prince and most of the blogs are written by people who have moved to Prince George or by those who have moved away and returned. This approach also helps people who have not heard of Prince George develop a positive perception of the city through third-party testimonials from people who made the move and love living in the city, and making them more likely to consider it as a viable place to live.

The website also offers a variety of tools employers can use to attract talent they need to sustain and expand their businesses. The website gives employers the ability to create accounts and post their employment opportunities for free to the website's built-in career search page. Employers also have access to the marketing campaign's digital graphics including web buttons and job banners that can be used to direct people to Move Up Prince George from their websites and digital job postings to learn more about living and working in Prince George. Employers can also 
request rack cards that list the "top 10 reasons" to move to Prince George to hand out at career fairs or to include in recruitment packages. Over the years, the campaign has evolved to include guided city tours at an employer's request for potential candidates who need to relocate to the city. The focus has also expanded to working with post-secondary institutions in Prince George to retain students post-graduation.

The City knew a website on its own would not do enough to attract new residents, which is why they coupled it with a national marketing, social media and media campaign to draw attention to the website and Prince George. The marketing campaign initially focused on five of the ten cities identified in the Workforce Intelligence Study as the best markets for Prince George employers and IPG to attract talent: Vancouver, Victoria, Edmonton, Toronto and Windsor. The focus was and remains on people aged 25-44 as this range includes people who are recent graduates or who have families and are looking for a more affordable community in which to live. The campaign initially involved a mixture of out-of-home and digital advertising including billboard ads, interior bus card ads, SkyTrain station poster ads, ads in university publications, Facebook ads and Google AdWords. This campaign has run every year since the initial launch, however, the budget and the focus on out-of-home ads have been reduced and an increased focus has been placed on digital ads. Facebook and Twitter accounts were created to share content developed for Move Up Prince George and to push people to the website. The initial media campaign garnered attention from media outlets in British Columbia and Alberta; additional media attention has been a result of reporters seeing advertisements.

As with all population attraction campaigns, measuring exactly how many people have moved to Prince George because of the Move Up Prince George campaign is difficult, which is why other measurements are relied on to determine the campaign's ongoing success. The number of employers who use the website is one measure: 272 employers were registered to post jobs on the Move Up Prince George website as of March 2018. Follow-up is conducted with employers at the end of the year to see how many jobs were filled and how many people moved to Prince George for jobs. Inquiries received because of Move Up Prince George have only been tracked since mid-2016; since tracking began, a total of 86 inquiries have been received through the website or associated social media. Website traffic is another success measurement: from the website's launch in August 2014 to March 2018, over 200,000 users have visited the website and numerous target geographic markets appear in the top 10 list of users including Vancouver, Calgary, Toronto, Edmonton and Victoria. Finally, the number of followers and the level of engagement on social media is another measure of the campaign's success. As of March 2018, the Facebook page had 4,200 likes and the Twitter feed had over 600 followers. The number of tours provided is also measured; the economic development division has not started actively promoting tours, but since early 2017, 12 tours have been given to potential candidates and 9 people have relocated to the city as a result. One person did not move because he was a recent graduate and his family did not want him to leave his hometown, one was interested in moving 
but his partner was not, and the third has not been offered the job yet. One of the best tools available to indirectly measure the campaign's success is the "Perceptions of Prince George" survey conducted by Malatest \& Associates Ltd. every three years. The most recent study was conducted in March 2017 and revealed an increase in awareness about Prince George in other Canadian cities where the survey was carried out and that perceptions had improved or remained the same from 2014 to 2017 (R.A. Malatest \& Associates Ltd., 2017). Additionally, people who had seen a Move Up Prince George advertisement were "less likely to view Prince George as a small and isolated community in rural BC" and "were more likely to say that they would prefer to live in a smaller city of 80,000" (R.A. Malatest \& Associates Ltd., 2017). Finally, although this cannot be attributed only to the campaign, the city experienced its first real population growth as of Census 2016, rising $2.8 \%$ to 74,003, which is the second highest growth percentage for Prince George since the beginning of the Census and the city's highest population since 1996 (Government of Canada, 2017b).

\section{Case study 3: Quesnel, BC-It's in our Nature}

Quesnel is a small city of just over 9,000 people located in the Cariboo region of BC, about anhour-and-a-half drive south of Prince George. Like Prince George, Quesnel is best-known for its natural resource industries, specifically forestry and mining. With the assistance of a marketing consultant, the City of Quesnel embarked on a year-long consultation with community members and local business to develop new branding, which was launched in February 2017. Previously known as the "Gold Pan City", which pays homage to the city's past ties with mining, the City's new brand logo is "Quesnel: It's in our nature" (Kurjata, 2017). According to Mayor Bob Simpson, the new brand looks forward to the future with a focus on its dependence upon nature for the well-being of its economy, but also implies that it is in the nature of people who live in Quesnel to be inviting and friendly (Kurjata, 2017).

Central to the branding process was the development of a communications strategy that outlines how best to promote the new brand and attract new residents to Quesnel. The strategy was developed by Stormy Lake Consultants, the firm hired to assist brand development, and identifies the fear of mill closures and the apprehension this causes in the community along with the relative lack of knowledge of Quesnel by those living outside Northern BC as the main factors that influenced brand development. The firm's goal was to "[d]evelop a brand and related actions that shift apprehension towards anticipation as we fulfill opportunities that guarantee sustainability" (Stormy Lake Consulting, 2017). The brand attributes are identified as trailblazing, sustainable, accessible and fun while focusing on retaining existing residents and attracting new residents and visitors (Stormy Lake Consulting, 2017). Communication around the brand focuses on attracting people to Quesnel from the densely populated and expensive Lower Mainland and Okanagan regions, focusing on the affordability of Quesnel, as well as shorter commute times (Kurjata, 2017). Social media channels developed to communicate 
information about Quesnel include Facebook and Instagram; both are used to encourage people to \#ExploreQuesnel. Efforts also include embedding brand messages in formal and informal speaking opportunities for the Mayor, Council and City Administration; advertising Quesnel on partner organization's websites, running a native advertising campaign to promote Quesnel in the summer and winter, which involves the use of paid ads that blend into the media format in which they appear rather than stand out as ads, working with local media to promote and share brandaligned stories, identifying influencers and inviting them to visit Quesnel, and purchasing outdoor advertising on Highways 1, 5 and 97 from Vancouver to Quesnel (Stormy Lake Consulting, 2017). This strategy complements a Red Carpet Welcome Program initiated to attract doctors to the city, which is in the process of being expanded to other businesses. In addition to the communications strategy, the municipality took actions to change policies to restructure taxes, to help preserve recreational opportunities, and to develop brand-driven development opportunities (Stormy Lake Consulting, 2017). The goal of these policy changes is to be future oriented and take risks to achieve economic growth.

As this strategy is new, access to success measurements are limited; however, as of March 2018 the Facebook page had over 1,500 likes and the Instagram page had almost 450 followers. According to Amy Reid, City of Quesnel Economic Development Officer, the biggest marker of success has been 25 requests for relocation packages through the website; this is five times the number they received the year prior to launching Explore Quesnel. Furthermore, the requests were received without any efforts to promote the link via advertising or other forms of marketing (A. Reid, personal communication, March 15, 2018).

\section{Retaining workers and elevating the existing workforce}

As highlighted in the case studies included in this paper, the strategies being employed by several medium and small resource-based cities in BC are slowly attracting new residents; however, this should not be the sole focus. Retaining existing workforces and providing access to

training for under-skilled residents to help business growth and attract new investment are also important to keeping populations and economies strong. According to the BC Labour Market Outlook: 2017, while the number of expected job openings by 2023 is expected to be a staggering 98,000,

"[1] ooking at job openings on a regional basis, two-thirds will be in the Mainland/Southwest, where employment is expected to grow annually by 1.3 percent. In all regions most jobs will result from replacement, rather than expansion. The Mainland/Southwest will lead in job openings resulting from expansion at 34 percent, while the North Coast/Nechako will see the least, at three percent" (BC Government, 2017). 
Prince George and Quesnel have started focusing on retention through their attraction strategies and by working directly with employers; however, more can be done to retain the existing workforce in resource-based communities such as these. Future actions could potentially include working with employers and post-secondary institutions to assist onboarding of new employees and welcoming new students to the community beyond just work and school environments. Actions could include offering driving tours to employees who are new to each community and providing them with welcome packages that provide information about living in each community. Workshops can be offered to human resource departments to provide them with employee retention strategies along with highlighting the importance of assisting new employees with settling in the communities. Ensuring new employees make immediate connections will increase the likelihood of them staying in their position and the new community for a longer period. Finally, efforts to create a network of like-minded people around new employees and engaging them in activities that they enjoy can be facilitated by economic developers by organizing and overseeing young-professional and other networking groups.

Economic developers can also work with local workforce developers to fill training gaps for those who are under-skilled and who are not being assisted by existing programs. This will also ensure training availability for people displaced from their jobs by the growing trend toward automation. As noted in 2017's BC Labour Market Outlook,

"By providing the right social supports many underemployed individuals will be able to rejoin the labour force. These include Indigenous people, women, people living with disabilities and both older and younger people. If labour demand continues to grow as expected and education and skills training programs continue to be made available to reduce barriers to employment, more people will be drawn into the labour force" (Government of BC, 2017).

While workforce developers already have many programs in place, there are still people in the groups identified who are not engaged in the workforce and need to develop skills to enter or reenter the workforce. Economic developers can also work with post-secondary institutions to ensure skills training aligns with current jobs and with jobs that are not impacted by automation.

\section{Conclusion}

Attracting workforce is becoming increasingly important for medium and small natural-resource based communities. The shift to a knowledge-based economy and growing urbanization of large urban centres draws away population and threatens the economic stability of these medium and small communities. Economic developers can play a critical role to help grow the population of their communities by marketing the strengths of their communities to position them as attractive places to live. These marketing strategies can have a positive effect as highlighted in the 
Kootenays, Prince George and Quesnel case studies. These case studies can help guide other communities across Canada facing similar difficulties to increase their competitive edge. However, marketing alone is not enough to build a sufficient workforce to attract new business. Communities must also work to retain their existing workforce and train members of the workforce who currently lack the skills to fill available jobs. If these steps are taken, medium and small resource-based communities will stand a better chance of diversifying their economies and remaining strong in the face of shifting economic realities.

\section{Author biography}

Christina Doll is the Workforce Development Officer in the Economic Development Division at the City of Prince George. She supports local business growth by implementing initiatives that assist in attracting and retaining population in Prince George. Prior to entering this role, she spent three years as the Manager, Marketing and Communications at the City's previous external economic development office, Initiatives Prince George. She holds a Certificate in Economic Development from the University of Waterloo, a Diploma in Public Relations from the University of Victoria, a Diploma, Broadcast and Media Communications with a specialization in Broadcast Journalism from the British Columbia Institute of Technology, and a Bachelor of Arts, English Literature from the University of Northern British Columbia.

\section{References}

Cocolakis-Wormstall, M. (2018). Labour Shortage: Here to Stay. Worker Scarcity in Canada and What Businesses Can Do to Respond. Business Development Bank of Canada.

Connery, T. (2016a, March 31). Imagine Kootenay: Good for Investment \& Business [Blog post]. Retrieved from http://www.lcic.ca/news/imagine-kootenay-good-local-investmentbusiness/

Connery, T. (2016b, May 12). New Billboard: Imagine Kootenay Increases Brand Profile! [Blog post]. Retrieved from https://imaginekootenay.com/new-billboard-imagine-kootenay-increasesbrand-profile/

Garmise, S., Ghosh, S., Thorstensen, L., Nourick, S., Girdwood, C. J., \& Bromley, I. (2015). Workforce Development: Canadian Edition. Washington, DC: International Economic Development Council. 
Government of BC. (2017, November). British Columbia Labour Market Outlook: 2017 Edition. Retrieved from https://www.workbc.ca/getmedia/66fd0e7c-734e-4fcb-b1a60454862525a6/BC_Labour_Market_Outlook_2017_Edition_Nov_2017.PDF.aspx

Government of Canada. (2017a, September 29). Maximizing Canada's Engagement in the Global Knowledge-Based Economy: 2017 and Beyond. Retrieved from http://www.horizons.gc.ca/en/content/maximizing-canada\%E2\%80\%99s-engagement-globalknowledge-based-economy-2017-and-beyond

Government of Canada. (2017b, November 16). Statistics Canada. Retrieved from http://www12.statcan.gc.ca/census-recensement/2016/dp$\mathrm{pd} /$ prof/details/page.cfm?Lang=E\&Geo1=CSD\&Code $1=5953023 \& G e o 2=\mathrm{CD} \&$ Code $2=5953 \& D$ $\underline{\text { ata }=\text { Count } \& \text { SearchText }=\text { prince } \% 20 \text { george } \& \text { SearchType }=\text { Contains } \& \text { SearchPR }=01 \& \mathrm{~B} 1=A 11 \& T A}$ $\mathrm{BID}=1$

Halseth, G., Markey, S., \& Ryser, L. (2015). State of Rural Canada: British Columbia. Retrieved from http://sorc.crrf.ca/bc/

Imagine Kootenays. Retrieved from https://imaginekootenay.com/

Kurjata, A., (2017, January 17). Short commutes, affordable housing: Quesnel rebrands itself to attract disenchanted Lower Mainland residents. Retrieved from http://www.cbc.ca/news/canada/british-columbia/short-commutes-affordable-housing-quesnelrebrands-itself-to-attract-disenchanted-lower-mainland-residents-1.3938564

Milner, M. (n.d.). Imagine Kootenay Success [Blog post]. Retrieved from http://kootenaybiz.com/west_kootenay/article/imagine_kootenay_success

O'Farrell, N. (2015, April 21). How to attract people to your city (and it's not just about jobs) [Blog post]. Retrieved from http://economicdevelopment.org/2015/04/how-to-attract-people-toyour-city-and-its-not-just-about-jobs/

One Acadiana. (2016, June 28). Fuel your future workforce: How to attract and retain professional talent [Blog post]. Retrieved from http://www.oneacadiana.org/news/201605/fuelyour-future-workforce-how-to-attract-and-retain-professional-talent

R.A. Malatest \& Associates. (2014, March 13). Workforce Development Study: Identifying Canadian Talent Pools for Prince George's In-Demand Occupations. Retrieved from https://www.princegeorge.ca/Business\%20and\%20Development/Economic\%20Development\%2 0Documents/InitiativesPrinceGeorgeWorkforceIntelligenceStudyFinalReportV2.pdf 
R.A. Malatest \& Associates. (2017, May 11). Perceptions of Prince George Report.

Stormy Lake Consulting. (2017, January 4). City of Quesnel Communications Plan. Retrieved from

https://www.quesnel.ca/sites/default/files/uploads/reports/quesnel_brand_communications_plan_ draft.pdf

WorkBC. (n.d). Labour Market Information. Regional Profile: Kootenay. Retrieved from https://www.workbc.ca/Labour-Market-Information/Regional-Profiles/Kootenay\#populationdistribution 